\title{
MASSA DE SEMENTES E PROFUNDIDADES DE SEMEADURA NO DESENVOLVIMENTO DE MUDAS DE TAMARINDEIRO ${ }^{1}$
}

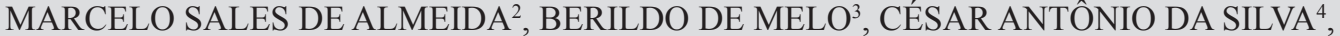 \\ DENISE GARCIA DE SANTANA ${ }^{5}$, CÍCERO JOSÉ DA SILVA ${ }^{6}$
}

RESUMO-Com o objetivo de avaliar a influência de massa de sementes e profundidades de semeadura sobre o vigor e o desenvolvimento vegetativo de mudas de tamarindeiro (Tamarindus indica L.), conduziu-se um experimento em viveiro telado, de malha $0,38 \mathrm{~mm}^{2}$, no Setor de Fruticultura da Fazenda Experimental Água Limpa, município de Uberlândia (MG), no período de 26 de dezembro de 2006 a 04 de junho de 2007. O delineamento experimental foi o inteiramente casualizado, com os tratamentos distribuídos em esquema fatorial 2 x 3 , com 5 repetições e 5 mudas por parcela, sendo os fatores: duas massas de sementes, leves e pesadas $(65,60 \mathrm{~g} / 100$ sementes; $94,54 \mathrm{~g} / 100$ sementes $)$, respectivamente, e três profundidades de semeadura (1; 2 e $3 \mathrm{~cm}$ ). Avaliaram-se o número de folhas, diâmetro do caule, altura da muda, comprimento da raiz principal, massas secas da parte aérea e de raízes. Os resultados demonstraram que sementes de maior massa proporcionam melhor desenvolvimento inicial das mudas. E quanto à profundidade de semeadura, não houve diferença significativa entre todas as características avaliadas.

Termos para indexação: Tamarindus indica L., propagação, classificação de sementes, profundidade.

\section{SEEDS WEIGHT AND SOWING DEPTHS IN THE DEVELOPMENT OF TAMARIND SEEDLINGS}

\begin{abstract}
The effect of seeds weight and different sowing depths on tamarind (Tamarindus indica L.) seedling vigor and vegetative growth was evaluated in a trial done in a screened nursery, with $0.38 \mathrm{~mm}^{2}$ opening, at the experimental farm Água Limpa, in a nursery with anti-aphid screens, in Uberlândia. The farm is located at $18^{\circ} 55^{\prime} 33^{\prime \prime} \mathrm{S}$ and $48^{\circ} 17^{\prime} 19^{\prime \prime} \mathrm{W}$, at $872 \mathrm{~m}$ altitude, in Minas Gerais state, from December $26^{\text {th }} 2006$ to June $4^{\text {th }} 2007$. The experimental design was randomized blocks, in a $2 \times 3$ factorial, with 5 repetitions and 5 plants per plot. The factors were two seeds weight, slight and weighty $(65.60 \mathrm{~g}$ and 94.54 $\mathrm{g}$ respectively), defined according to the weight of 100 seeds and three sowing depths $(1 \mathrm{~cm} ; 2 \mathrm{~cm}$ or $3 \mathrm{~cm})$. The number of leaves, stem diameter, plant height, root length, fresh and dries weight of roots and above ground matter were evaluated. The results indicated that the weighty seeds provided the best seedlings initial development. There were no significant differences among the parameters evaluated compared with the function of sowing depth.
\end{abstract}

Index terms: Tamarindus indica L., propagation, seeds classification, depth.

\footnotetext{
'(Trabalho 071-09). Recebido em: 31-03-2009. Aceito para publicação em: 24-02-2010. Trabalho redigido a partir da Dissertação de Mestrado do primeiro autor.

${ }^{2}$ Ms. em Agronomia (Fitotecnia) pela Universidade Federal de Uberlândia (UFU), Uberlândia, Minas Gerais. E-mail: marceloufu@gmail.com ${ }^{3}$ Dr. em Agronomia (Fitotecnia) pela Universidade Federal de Lavras, Prof. Titular de Fruticultura na Universidade Federal de Uberlândia. E-mail: berildo@ufu.br

${ }^{4}$ Doutorando em Agronomia (Irrigação e Drenagem) na Universidade de São Paulo (ESALQ/USP). E-mail: cesarsilva@usp.br ${ }^{5}$ Dra. em Agronomia (Estatística e Experimentação Agronômica) pela ESALQ/USP. Prof. Adjunto II de Experimentação Agrícola na UFU. E-mail: dgsantana@umuarama.ufu.br

${ }^{6}$ Mestrando em Agronomia (Fitotecnia) na UFU. E-mail: cicerojosedasilva@yahoo.com.br
} 


\section{INTRODUÇÃO}

O tamarindeiro (Tamarindus indica L.) é uma frutífera cultivada há séculos no Brasil e de importância na alimentação humana pela destinação dos frutos à produção de sorvetes, tortas, balas, licores, doces e, principalmente, sucos concentrados (FERREIRA et al., 2008). A polpa apresenta composição química bastante variável, destacando-se o alto valor calórico (340 calorias/100 g de polpa), os teores de sólidos solúveis $(54,0$ a $69,8 \%)$ e de proteínas $(1,4$ a 3,4\%), e a elevada acidez (SILVA, 2007). O tamarindeiro é, também, utilizado para fins ornamentais e arborização, devido à sua beleza e produção de sombra, apesar do crescimento lento, que depende, fundamentalmente, da utilização de mudas de qualidade.

A produção de mudas sadias e bem desenvolvidas é um fator de extrema importância para qualquer cultura, principalmente as perenes como o tamarindeiro. Mudas de alto vigor, produzidas conforme os padrões de qualidade, são determinantes ao sucesso do pomar, proporcionando maior produtividade e redução de custos.

De acordo com Araújo et al. (2009), fatores como densidade (relação massa/volume), profundidade e posição da semente na ocasião da semeadura influenciam na germinação e, consequentemente, no desenvolvimento das plântulas. A massa das sementes é característica a ser considerada quando da propagação de frutíferas, razão para a realização de uma série de estudos para tentar classificar adequadamente as sementes de diferentes espécies vegetais. Entretanto, os resultados têm sido divergentes, mesmo em se tratando de sementes da mesma espécie. Nesse sentido, alguns trabalhos com várias espécies, inclusive o tamarindeiro, constataram relação positiva entre o tamanho da semente e a qualidade das mudas (FONSECA, 1979; MELO, 1999; PEREIRA, 2005).

O tamanho das sementes de muitas espécies pode ter relação com o potencial fisiológico destas. Conforme Popinigis (1977), germinação e vigor superiores são apresentados por sementes grandes e médias de um lote, em relação às de menor tamanho. Parameswari et al. (2001) e Silva (2007) constataram plântulas de tamarindeiro mais vigorosas quando oriundas de sementes da classe de maior tamanho.

Favarin et al. (2003), em estudo com sementes de café, referiram-se ao crescimento do embrião como dependente da quantidade de reservas do endosperma que pode, ou não, estar relacionada ao tamanho da semente. Geralmente, a massa da semente tem relação positiva com o seu tamanho e o teor de água, mas, conforme as condições reinantes durante o desenvolvimento da mesma, podem ser produzidas sementes com massas diferentes e tamanhos semelhantes. Desse modo, o ideal é também classificá-las conforme a massa.

Pereira et al. (2008) verificaram que sementes de classes de maior massa (77,6 e 68,7 g/100 sementes) originaram mudas de tamarindeiro de melhor qualidade, quanto ao diâmetro de caule, altura e massas de matérias secas da parte aérea e de raízes, em relação às de classes de 21,7 e 46,6 g/100 sementes.

Semeaduras muito profundas dificultam a emergência das plântulas e aumentam o período de suscetibilidade a patógenos (MARCOS FILHO, 2005). Por outro lado, semeaduras rasas podem facilitar o ataque de predadores ou danos decorrentes da irrigação ou, ainda, a exposição e a destruição da radícula (JELLER; PEREZ, 1997). Fonseca et al. (1994) referiram-se à profundidade ideal de semeadura como aquela na qual ocorre germinação homogênea das sementes, rápida emergência das plântulas e produção de mudas vigorosas. Profundidades iguais ou superiores a $3,0 \mathrm{~cm}$ são inadequadas para semeadura de açaí (Euterpe oleracea Mart.) (SILVA et al., 2007). Estes autores verificaram menor tempo de emergência de plântulas quando as sementes foram posicionadas com a rafe perpendicularmente à superfície do substrato e o poro germinativo voltado para cima.

Estudos básicos sobre a profundidade de semeadura fazem-se necessários, tendo em vista a existência de controvérsias sobre a profundidade ideal para a produção de mudas de frutíferas. Para espécies como o maracujazeiro-amarelo, foram recomendadas as profundidades de semeadura de $2,0 \mathrm{~cm}$ (SÃO JOSÉ, 1991), 1,5 cm (TEIXEIRA et al., 1994) e 1,0 cm (RIZZI et al., 1998; MELETTI; MAIA, 1999). Estes valores são superiores ao sugerido por Deichmann (1967) ao relatar que a profundidade de semeadura deve ser proporcional às dimensões da semente. Contudo, Silva (2006) verificou a emergência mais rápida de plântulas de maracujazeiro em semeadura a $2,0 \mathrm{~cm}$, comparativamente às sementes dispostas a 1,0 e $1,5 \mathrm{~cm}$ de profundidade.

Diante dessas divergências, o objetivo do trabalho foi avaliar o desenvolvimento de mudas de tamarindeiro (Tamarindus indica L.) em função da profundidade de semeadura e massas de sementes. 


\section{MATERIAL E MÉTODOS}

O experimento foi conduzido na Fazenda Experimental Água Limpa, município de Uberlândia (MG), em viveiro situado a $19^{\circ} 05^{\prime} 23$ " de latitude sul, $48^{\circ} 21^{\prime} 28^{\prime \prime}$ de longitude oeste e a uma altitude de, aproximadamente, $798 \mathrm{~m}$, no período de $26 \mathrm{de}$ dezembro de 2006 a 04 de junho de 2007. O viveiro, de $10 \mathrm{~m}$ de comprimento, $6,0 \mathrm{~m}$ de largura e $2,0 \mathrm{~m}$ de altura e com telado antiafídico, de malha $0,38 \mathrm{~mm}^{2}$ e de cor branca, dispunha de bancadas de madeira de 1,0 m de largura, suspensas a uma altura de 1,0 $\mathrm{m}$ em relação ao nível do solo para a colocação dos recipientes.

Foram colhidas sementes de duas plantas de tamarindeiro (Tamarindus indica L.) no estádio de maturação fisiológica do fruto, o qual coincide com o seu desprendimento natural da planta-matriz. As sementes foram despolpadas sobre peneira em água corrente e armazenadas por 30 dias sob refrigeração entre 4 e $8^{\circ} \mathrm{C}$ e, em seguida, aplicado um procedimento para a superação da sua dormência, correspondente à manutenção por 24 horas em temperatura ambiente, com posterior imersão em água na temperatura ambiente por mais 24 horas, conforme descrito por Pereira et al. (2009). Em seguida, foi realizada a semeadura.

O delineamento experimental foi o inteiramente casualizado, com os tratamentos distribuídos em esquema fatorial $2 \times 3$, com cinco repetições e cinco mudas por parcela, totalizando 150 mudas. O primeiro fator correspondeu a duas massas de sementes, leves e pesadas $(65,60$ e 94,54 g/100 sementes, respectivamente), enquanto o segundo correspondeu a três profundidades de semeadura $(1,0 ; 2,0$ e $3,0 \mathrm{~cm})$.

Na semeadura, foram dispostas três sementes por recipiente. Os recipientes usados no experimento foram sacos plásticos de forma cilíndrica, $\operatorname{com} 25 \mathrm{~cm}$ de diâmetro interno e $35 \mathrm{~cm}$ de altura, confeccionados em material de polipropileno pigmentado contra raios ultravioleta e perfurados até $1 / 3$ da altura. Foi utilizado o substrato comercial Bioplant, para o enchimento dos recipientes, constituído de casca de pínus compostada e carbonizada, enriquecido de nutrientes. Aos 35 dias após a semeadura, com a altura das mudas entre 3 e $5 \mathrm{~cm}$, foi realizado o desbaste, com auxílio de tesoura de poda, deixando-se somente uma muda por recipiente.

Adubações suplementares foram realizadas aos 45 e 90 dias após a semeadura, adicionandose 2,0 $\mathrm{g}$ de ureia, 3,0 $\mathrm{g}$ de superfosfato simples e 2,0 g de $\mathrm{KCl}$ por litro de água, com emprego de dosador manual. Plantas daninhas eventuais foram manualmente eliminadas, semanalmente. Irrigações foram realizadas diariamente com sistema de microaspersão, dotado de emissores do tipo "bailarina", instalados a 2,0 metros de altura em relação à superfície do solo, com vazão de $120 \mathrm{~L} \mathrm{~h}^{-1}$, espaçados três metros entre si. Durante o experimento, não foram aplicados defensivos químicos em razão da ausência de sintomas de doenças ou ataque de pragas que prejudicassem o desenvolvimento das mudas.

As avaliações foram realizadas aos 160 dias após a semeadura, mediante a mensuração da altura $(\mathrm{cm})$, do comprimento da raiz principal $(\mathrm{cm})$, do diâmetro de caule $(\mathrm{mm})$, do número de folhas e das massas de matérias secas da parte aérea e do sistema radicular $\left(\mathrm{g} \mathrm{muda}^{-1}\right)$, das plântulas. O sistema radicular foi removido dos sacos plásticos após destacada a parte aérea das plântulas com o auxílio de um estilete, sendo as raízes lavadas em água corrente. Então, todo o material foi acondicionado em embalagens de papel e submetido à circulação de ar forçado, em estufa a $65^{\circ} \mathrm{C}$, até atingir massa constante.

Os dados foram submetidos à análise de variância (teste $\mathrm{F}$ ) em níveis de 0,01 e 0,05 de significância e, em seguida, as médias foram comparadas, utilizando o teste de Tukey, a 5\% de probabilidade, conforme descrito por Banzatto e Kronka (2006), com emprego do software SISVAR.

\section{RESULTADOS E DISCUSSÃO}

Na Tabela 1, é apresentado o resumo das análises de variância dos dados das características altura, diâmetro de caule, número de folhas, comprimento da raiz principal e massas de matérias secas de raízes e da parte aérea das mudas de tamarindeiro em função da massa de sementes e da profundidade de semeadura. Não foram constatadas significâncias da interação massa de sementes $\mathrm{x}$ profundidade de semeadura, bem como deste último fator, isoladamente, no desenvolvimento das mudas. Estes resultados diferem do encontrado por Silva et al. (2007) com a cultura do açaí, ao verificarem maior tempo médio de emergência e redução do desenvolvimento das plântulas em semeadura a 3,0 cm de profundidade, em relação à semeadura mais rasa. Provavelmente, em parte, o fato possa ser atribuído às diferenças entre dimensões e/ou quantidade de substâncias de reserva nas sementes das duas espécies.

As características altura e massas de matérias secas de raízes e da parte aérea, a $1 \%$ de probabili- 
dade pelo teste $\mathrm{F}$, e o diâmetro de caule das mudas, ao nível de $5 \%$ de probabilidade, indicam efeito isolado do fator massa de sementes.

Conforme a Tabela 2, mudas de tamarindeiro com maior altura e diâmetro de caule, quando provenientes de sementes de maior massa, foram observadas, resultados consoantes aos obtidos por Silva (2007) e Pereira et al. (2008). Outros trabalhos, como os de Fonseca (1979) e Valeri et al. (1984), com sementes de eucalipto, demonstraram resultados semelhantes.

Os maiores valores de massas de matérias secas de raízes e da parte aérea foram verificados nas mudas oriundas de sementes de maior peso (Tabela
3), diferindo significativamente daquelas provenientes de sementes leves. Tais resultados podem ser atribuídos à quantidade de reservas da semente, como fonte de nutrientes para o crescimento inicial.

Segundo Parameswari et al. (2001), plântulas de tamarindeiro mais vigorosas e com massa de matéria seca superior foram observadas quando originadas de sementes de maior tamanho. Os resultados obtidos quanto à massa de sementes seguem a mesma tendência para todas as características avaliadas, exceto número de folhas e comprimento da raiz principal. Consequentemente, a vantagem de se utilizarem sementes de maior massa consiste no menor tempo de permanência das mudas no viveiro e para o plantio definitivo das mesmas no campo.

TABELA 1 - Resumo das análises de variância da altura (ALT), diâmetro de caule (DC), número de folhas (NF), comprimento da raiz principal (CR), massa seca de raízes (MSR) e da parte aérea (MSPA) de mudas de tamarindeiro, aos 160 dias após a semeadura, em função de massa de sementes e profundidade de semeadura.Uberlândia - MG, 2007.

\begin{tabular}{lccccccc}
\hline & & \multicolumn{7}{c}{ Quadrado Médio } \\
\cline { 3 - 8 } \multicolumn{1}{c}{ Fator de Variação } & GL & $\begin{array}{c}\text { ALT } \\
(\mathrm{cm})\end{array}$ & $\begin{array}{c}\text { DC } \\
(\mathrm{mm})\end{array}$ & NF & $\begin{array}{c}\text { CR } \\
(\mathrm{cm})\end{array}$ & $\begin{array}{c}\text { MSR } \\
(\mathrm{g})\end{array}$ & $\begin{array}{c}\text { MSPA } \\
(\mathrm{g})\end{array}$ \\
\hline Massa de sementes (M) & 1 & $860,495^{* *}$ & $25,724^{*}$ & $300,833^{\mathrm{NS}}$ & $75,208^{\mathrm{NS}}$ & $21,539^{* *}$ & $46,700^{* *}$ \\
Profundidade de semeadura (P) & 2 & $55,226^{\mathrm{NS}}$ & $2,585^{\mathrm{NS}}$ & $202,806^{\mathrm{NS}}$ & $25,568^{\mathrm{NS}}$ & $1,667^{\mathrm{NS}}$ & $4,113^{\mathrm{NS}}$ \\
M x P & 2 & $5,942^{\mathrm{NS}}$ & $5,417^{\mathrm{NS}}$ & $248,885^{\mathrm{NS}}$ & $97,298^{\mathrm{NS}}$ & $1,242^{\mathrm{NS}}$ & $3,990^{\mathrm{NS}}$ \\
Resíduo & 24 & 70,755 & 5,850 & 132,449 & 64,300 & 0,913 & 2,751 \\
\hline CV (\%) & & 20,92 & 38,37 & 37,17 & 13,66 & 19,79 & 29,34 \\
Média geral: & 40,21 & 6,30 & 30,96 & 58,69 & 4,83 & 5,65 \\
\hline
\end{tabular}

**, * - Significativo a $1 \%$ e $5 \%$ de probabilidade, pelo teste $\mathrm{F}$, respectivamente

Ns - Não significativo

TABELA 2 - Altura de plantas e diâmetro de caule de mudas de tamarindeiro, aos 160 dias após a semeadura, em função de massa de sementes e profundidade de semeadura. Uberlândia - MG, 2007.

\begin{tabular}{lccccc}
\hline \multirow{2}{*}{ Característica avaliada } & \multirow{2}{*}{ Massa de sementes } & \multicolumn{3}{c}{ Profundidade de semeadura (cm) } & \multirow{2}{*}{ Média } \\
\cline { 2 - 5 } & & 1,0 & 2,0 & 3,0 & \\
\hline \multirow{3}{*}{ Altura de plantas (cm) } & Leve & 35,56 & 36,40 & 32,60 & $34,85 \mathrm{~b}$ \\
& Pesada & 44,83 & 48,73 & 43,13 & $45,56 \mathrm{a}$ \\
\cline { 2 - 5 } & Média & $40,20 \mathrm{a}$ & $42,56 \mathrm{a}$ & $37,86 \mathrm{a}$ & 40,21 \\
\hline \multirow{2}{*}{ Diâmetro de caule $(\mathrm{mm})$} & Leve & 5,56 & 5,45 & 5,12 & $5,38 \mathrm{~b}$ \\
& Pesada & 6,25 & 6,81 & 8,63 & $7,23 \mathrm{a}$ \\
\cline { 2 - 5 } & Média & $5,91 \mathrm{a}$ & $6,13 \mathrm{a}$ & $6,88 \mathrm{a}$ & 6,30 \\
\hline
\end{tabular}

Médias seguidas pela mesma letra não diferem entre si, pelo teste de Tukey, a 0,05 de significância. 
TABELA 3 - Massa seca de raízes e da parte aérea de mudas de tamarindeiro, aos 160 dias após a semeadura, em função de massa de sementes e profundidade de semeadura. Uberlândia - MG, 2007.

\begin{tabular}{cccccc}
\hline \multirow{2}{*}{ Característica avaliada } & \multirow{2}{*}{ Massa de sementes } & \multicolumn{3}{c}{ Profundidade de semeadura (cm) } & \multirow{2}{*}{ Média } \\
\cline { 2 - 5 } & & 1,0 & 2,0 & 3,0 & \\
\hline \multirow{2}{*}{$\begin{array}{c}\text { Massa seca de raízes } \\
\left(\mathrm{g} \mathrm{muda}^{-1}\right)\end{array}$} & Leve & 4,54 & 4,05 & 3,35 & $3,98 \mathrm{~b}$ \\
& Pesada & 5,43 & 6,23 & 5,37 & $5,68 \mathrm{a}$ \\
\cline { 2 - 5 } & Média & $4,98 \mathrm{a}$ & $5,14 \mathrm{a}$ & $4,36 \mathrm{a}$ & 4,83 \\
\hline \multirow{2}{*}{ Massa seca da parte aérea } & Leve & 5,16 & 4,38 & 3,67 & $4,40 \mathrm{~b}$ \\
\cline { 2 - 5 }$\left(\mathrm{g} \mathrm{muda}^{-1}\right)$ & Pesada & 6,35 & 8,09 & 6,26 & $6,90 \mathrm{a}$ \\
\cline { 2 - 5 } & Média & $5,76 \mathrm{a}$ & $6,24 \mathrm{a}$ & $4,97 \mathrm{a}$ & 5,65 \\
\hline
\end{tabular}

Médias seguidas pela mesma letra não diferem entre si, pelo teste de Tukey, a 0,05 de significância.

\section{CONCLUSÕES}

1-O desenvolvimento de mudas de tamarindeiro é influenciado positivamente pela massa das sementes, mas não pela profundidade de semeadura até o limite de $3,0 \mathrm{~cm}$.

2-Maior massa, por 100 sementes de tamarindeiro, propicia mudas de maior altura, diâmetro de caule e massa seca de raízes e da parte aérea.

\section{REFERÊNCIAS}

ARAUJO, J. R. G.; CERQUEIRA, M. C. M.; GUISCEM, J. M.; MARTINS, M. R.; SANTOS, F. N. dos; MENDONÇA, M. C. S. Embebição e posição da semente na germinação de clones de porta-enxertos de cajueiro-anão-precoce. Revista Brasileira de Fruticultura, Jaboticabal, v. 31, n. 2, p. 552-558, 2009.

BANZATTO, D. A.; KRONKA, S. do N. Experimentação agrícola. 4. ed. Jaboticabal: FUNEP, 2006. 237 p.

DEICHMANN, V. Noções sobre sementes e viveiros florestais. Curitiba: Escola de Florestas, 1967. 196p.

FAVARIN, J. L.; COSTA, J. D.; NOVEMBRE, A. D. C.; FAZUOLI, L. C.; FAVARIN, M. G. G. V. Características da semente em relação ao seu potencial fisiológico e à qualidade de mudas de café (Coffea arabica L.). Revista Brasileira Sementes, Pelotas, v. 25, n. 2, p. 2-11, 2003.

FERREIRA, E. A.; MENDONÇA, V.; SOUZA, H. A. de; RAMOS, J. D. Adubação fosfatada e potássica na formação de mudas de tamarindeiro. Scientia Agrária, Curitiba, v. 9, n. 4, p. 475-480, 2008.
FONSECA, A. G. Efeito do sombreamento, tamanho e peso de sementes na produção de mudas de Eucalyptus grandis W. Hill ex Maiden e no seu crescimento inicial no campo. 1979. 63 f. Dissertação (Mestrado em Ciência Florestal) - Universidade Federal de Viçosa, Viçosa, 1979.

FONSECA, C. E. L.; FIGUEIREDO, S. A.; SILVA, J. A. Influência da profundidade de semeadura e da luminosidade na germinação de sementes de baru (Dipteryx alata Vog.). Pesquisa Agropecuária Brasileira, Brasília, v. 29, n.4, p. 653-659. 1994.

JELLER, H.; PEREZ, S. C. J. G. de A. Efeito da salinidade e semeadura em diferentes profundidades na viabilidade e no vigor de Copaifera langsdorffii Desf.- Caesalpiniaceae. Revista Brasileira de Sementes, Pelotas, v.19, n. 2, p. 218-224, 1997.

MARCOS FILHO, J. Fisiologia de sementes de plantas cultivadas. Piracicaba: FEALQ, 2005. $495 \mathrm{p}$.

MELETTI, L. M. M.; MAIA, M. L. Maracujá: produção e comercialização. Campinas: Instituto Agronômico, 1999. p. 20-25.

MELO, B. Estudos sobre produção de mudas de cafeeiro (Coffea arabica L.) em tubetes: tipos de fertilização e diferentes substratos na produção de mudas de cafeeiro (Coffea arabica L.) em tubetes. 1990, 119 f. Tese (Doutorado em Fitotecnia) - Universidade Federal de Lavras, Lavras, 1999.

PARAMESWARI, K.; SRIMATHI, P.; MALARKODI, K. Influence of seed size and duration of acid scarification on seed germination of tamarind (Tamarindus indica Linn.). Agriculture Journal, Madras, v. 88, n.1/3, p. 56-60, 2001. 
PEREIRA, P. C. Avaliação da qualidade de mudas de tamarindeiro produzidas em viveiro. 2005. 71 f. Dissertação (Mestrado em Agronomia) - Universidade Federal de Uberlândia, Uberlândia, 2005.

PEREIRA, P. C.; FREITAS, R. S. de; MELO, B. de; FRANZÃO, A. A.; PEREIRA, A. P.; SANTANA, J. das G.; LUZ, J. M. Q.; MARTINS, M. Influência do tamanho de sementes na qualidade de mudas de tamarindeiro. Bioscience Journal, Uberlândia, v. 24, n. 4, p. 73-79, 2008.

PEREIRA, P. C.; MELO, B.; FRANZÃO, A. A.; ALVES, P. R. B. A cultura do tamarindeiro. Uberlândia: UFU. Disponível em: <www.fruticultura. iciag.ufu.br>. Acesso em: 15 ago. 2009.

POPINIGIS, F. Fisiologia da semente. Brasília: AGIPLAN, 1977. 289p.

RIZZI, L. C.; RABELLO, L. R.; MOROZINI FILHO, W.; SAVAZAKI, E. T.; KAVATI, R. Cultura do maracujá-azedo. Campinas: CATI, 1998. p. 2-7. (Boletim Técnico, 235).

SÃO JOSÉ, A. R. Propagação do maracujazeiro. In: SÃO JOSÉ, A. R.; FERREIRA, F. R. e VAZ, R. L. A cultura do maracujá no Brasil. Jaboticabal: Funep, 1991. p. 61-62.

SILVA, A. P. P. da. Desenvolvimento de mudas de maracujazeiro-amarelo em tubetes. 2006. 84f. Dissertação (Mestrado em Agronomia) - Universidade Federal de Uberlândia, Uberlândia, 2006.
SILVA, B. M. da S.; MÔRO, F. V.; SADER, R.; KOBORI, N. N. Influência da posição e da profundidade de semeadura na emergência de plântulas de açaí (Euterpe oleracea Mart. - Arecaceae). Revista Brasileira de Fruticultura, Jaboticabal, v. 29, n. 1, p. 187-190, 2007.

SILVA, C. A. Qualidade de mudas de tamarindeiro formadas a partir de classes de sementes e fontes de matéria orgânica. 2007. 25 f. Monografia (Trabalho de Graduação em Agronomia) - Universidade Federal de Uberlândia, Uberlândia, 2007.

TEIXEIRA, C. G.; CASTRO, J. V. de; TOCCHINI, R. P.; NISIDA, A. L. A. C.; HASHUZUME, T.; MEDINA, J. C.; TURATTI, J. M.; LEITE, R. S. da S. F.; BLISKA, F. M. de M.; GARCIA, A. E. B Maracujá: cultura, matéria-prima, processamento e aspectos econômicos. Campinas: ITAL, 1994. p. 38-46. (Série Frutas Tropicais, 9).

VALERI, S. V.; AGUIAR, I. B.; DENARDI, M. A. Influência do tamanho de sementes de Eucalyptus saligna no desenvolvimento das mudas produzidas através dos métodos de semeadura e repicagem. In: SIMPÓSIO INTERNACIONAL: MÉTODOS DE PRODUÇÃO E CONTROLE DE QUALIDADE DE SEMENTES E MUDAS FLORESTAIS, 1984, Curitiba. Anais... Curitiba: UFPr, 1984. p. 109-121. 